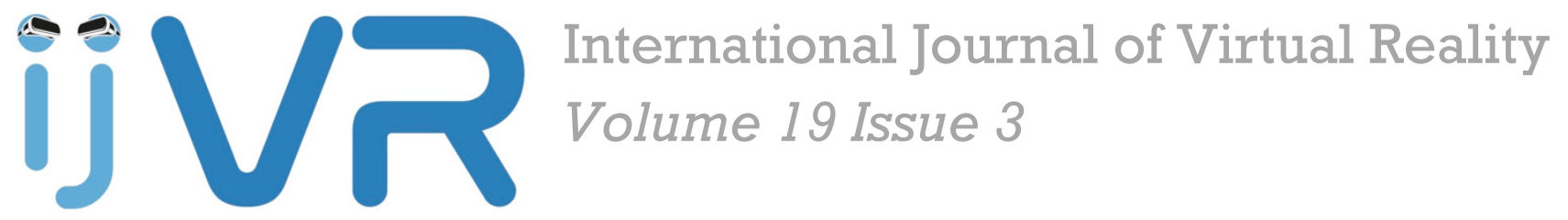

IPI Press

ISSN: 1081-1451

Engelmann, T., Wallstein, S., \& Hitzler, D. (2019). An Experimental Study to Investigate the Potential of Online Shopping in Immersive Virtual Realities Compared to Conventional Online Shops. International Journal of Virtual Reality, 19(3), 31-45.

https://doi.org/10.20870/IJVR.2019.19.3.2939

CC BY 4.0 license

Received: 05/2019

Published: 11/2019 


\title{
An Experimental Study to Investigate the Potential of Online Shopping in Immersive Virtual Realities Compared to Conventional Online Shops
}

\author{
Tanja Engelmann ${ }^{1}$, Sabine Wallstein ${ }^{2}$, Dieter Hitzler ${ }^{3}$ \\ ${ }^{1}$ Macromedia University of Applied Sciences, Business Faculty, Stuttgart, Germany \\ ${ }^{2}$ Macromedia University of Applied Sciences, Media Faculty, Munich, Germany \\ ${ }^{3}$ Macromedia University of Applied Sciences, Media Faculty, Stuttgart, Germany
}

Corresponding author: Tanja Engelmann, ta.engelmann@macromedia.de

Keywords: Virtual Reality - online shopping - conventional shopping - experimental study

\begin{abstract}
Immersive virtual reality technology enables the experience of feeling 'presence', that is, to have the feeling of being in an immersive computer-supported room. Because these technologies are used increasingly in private households, retailers are very interested in using them as a new sales opportunity. In our experimental study we investigated whether VR-based online shops could be more profitable for them compared to conventional online shops. The following results were found: A VR-based online shop generated a more real perception of the objects, and more interest in buying them. In addition, the shopping experience in the VRbased online shop was perceived as very exciting. However, the amount of acquired knowledge and the influence on the attitude of the buyer seemed to depend on the object type. Despite the limitations of this experimental study due to its focus on internal validity, the results point to the potential of immersive VRbased online shops as a new distribution channel.
\end{abstract}

\section{Introduction}

Virtual Reality (VR) is currently one of the most promising emerging technologies in terms of business innovation (Plummer et al., 2016). The impact of VR on gaming, entertainment, education, product design, communications, and other fields is constantly increasing (Barnes, 2017). Therefore, it is not surprising that retailers are also interested in using this technology to sell their products. This is especially the case since VR-technology has been made easily and affordably accessible for private households by the availability of smartphone-enabled headsets, such as Samsung Gear VR and Google Cardboard-type devices (Van Kerrebroeck et al., 2017). According to the International Data Cooperation, 2.1 million AR and VR headsets were sold worldwide in the second quarter of 2017, the majority with VR glasses (Brandt, 2017).

Therefore, this is the research question of this exploratory paper: Is selling products in a VR-based online shop more profitable than in a conventional, non-immersive online shop? To answer this research question, an experimental study is presented in this paper, in which 50 participants took part in.

The current paper is structured as follows: We first describe the distribution channel of e-commerce and accordingly online shopping. After that, we focus on the topic of virtual reality, before we describe how virtual reality in online shops is already used, and why it is expected to be a profitable possibility for selling objects.

Subsequently, the empirical study is presented, investigating whether VR-based online shops are more profitable as selling platforms compared to conventional online shops. The paper ends with a discussion of the study results, an explication regarding the limitations of the study and conclusions. 


\section{E-Commerce and Online Shopping}

Online shopping is an important part of e-commerce (Siepermann, 2018). E-commerce (also called electronic commerce) refers to the use of the Internet for buying and selling products (Chaffey et al., 2019). Since it began in 1995, global e-commerce has grown from a standing start to a $€ 1.96$ billion business-to-consumer and a $€ 14.2$ trillion business-to-business juggernaut, bringing about enormous changes in business firms, markets, and consumer behavior (Laudon and Traver, 2016). There is still hardly any industry or product group that is not present in one or another way via e-commerce (Riehm at al., 2003).

During this relatively short time, e-commerce has itself been transformed from its origin as a mechanism for online retail sales into something much broader. Today, e-commerce has become the platform for media and new, unique services and capabilities that are not found in the physical world. For example, there is no physical world counterpart to Facebook, Twitter, Google search, or a host of other recent online innovations from Pinterest and iTunes to Tumblr (Laudon and Traver, 2016).

Online shopping as a part of e-commerce involves purchasing products or services over the internet as the main means of exchange (Siepermann, 2018). Here the focus is on the customer side. In online stores, all the products are described through text, complemented by photos and multimedia files. A few online shops provide additional links to extra information about their products. Furthermore, many online stores allow users to rate their products, offering the opportunity to search for product reviews that other customers may have posted.

There are lot of advantages to online shopping; the most obvious one is convenience. As long as there is a computer on the desk, online shopping is possible from anywhere. There is no need to take the time to travel to a conventional store. Also, online stores typically operate 24 hours a day and seven days a week, so it is not necessary to rush to get there during business hours (Leadem, 2017). Furthermore, with online shopping, there is also no need to wait in queues at the checkout once you get your items. There is no requirement to lift any heavy or awkward sized and shaped packages. Shopping hardly requires any physical effort: simply select by click and deposit items in a digital shopping trolley. The items are usually delivered by post. Search engines and online price comparisons are useful to find sellers of a specific product. It is also possible to find good deals on various items very quickly and some items will generally be cheaper if bought over the internet. So online shopping offers convenience as well as savings in time and energy (Leadem, 2017). According to Eurostat (2018), almost 7 out of 10 internet users made online purchases in 2017. Overall, the number of e-shoppers is growing, especially in the age groups 16 to 24 and 25 to 54, where in both cases 73 $\%$ are already e-shoppers (Eurostat, 2018).

To show why new technology will play an important role in the further growth of e-commerce, or rather online shopping, we now explain what virtual reality is (chapter 3) and what potential it has for online shopping (chapter 4).

\section{Virtual Reality}

The rise of Virtual Reality in the last decade has been perceived as a trend. This is important to the extent that companies are always interested in new concepts and applications to reach their customers (Grewal et al., 2017). The words virtual and reality make explicit enough what Virtual Reality is about. The Virtual Reality Society defines virtual as "near" and reality as what we experience as human beings through our senses: taste, touch, smell, sight, and hearing (Virtual Reality Society, 2017). VR is usually implemented using dedicated computer technology through special systems (Velev and Zlateva, 2019). For more detail, a computer-generated 3D environment in which the consumer is encircled is necessary. In addition, the 3D environment responds in a natural way (Cearley et al., 2017). This means that with the use of computer technology, the effect of an interactive three-dimensional world is created in which the subjects have a sense of spatial presence (NASA, 2016). This feeling of presence is realized by an immersive head-mounted display (HMD), which generally covers the consumer's entire field of sight. Additional components, for example handheld controllers or gesture recognition, can provide hand and body tracking. Furthermore, touch-sensitive feedback may be integrated (Cearley et al., 2017). Consequently, human senses will be activated in order to create the illusion of reality (Velev and Zlateva, 2019). According to Gorisse et al. 
(2017), presence is a complex concept, which is analyzed in disciplinary fields and not restricted to virtual environments. They define presence as "for someone or something, of being physically in a certain place, as opposed to absence" (p. 2). Pillai et al. (2013) added that presence is not only being there, but also a mixture of multiple feelings and a significant experiencing of reality. With a stronger relationship to virtual reality Grudzewski et al.(2018) point out that the experience of presence in an environment is evoked by means of a communication medium.

Steuer (1992) - a pioneer in VR research - pointed out two crucial components regarding the sense of being present: 'vividness' as the representational richness of a mediated environment, and 'interactivity' in terms of the extent to which users can participate in modifying the form and content of a mediated environment in real time. Technologies such as Virtual Reality allow higher levels of vividness and interactivity, as compared to traditional media (Van Kerrebroeck et al., 2017). Van Kerrebroeck et al. (2017) describe vividness in more detail, referring to the dimensions of breadth and depth. They point out that the number of sensory dimensions and senses presented, that is called breadth, and the quality and resolution of the presentation, that is called depth, have an impact on the feeling of presence. Regarding vividness, imagery richness seems to be crucial in product presentations and marketing communications, as it enables more realistic representations of products or environments. Imagery richness can be affected by, for example, audio, video, or animation (Cheng et al., 2014). Barnes mentions another important driver for the feeling of presence, namely the "tendency of individuals to experience flow" (Barnes, 2017). He states that flow can increase immersion. First introduced by Csikszentmihalyi (1990), flow is defined as the feeling that occurs when an individual is in a state of optimum condition, fully absorbed and immersed in an activity (Nah et al., 2014). Mütterlein (2018) explicitly points out that all these aspects - the influence of flow and immersion, interactivity, and presence on the user's perception in VR environments - are important for the VR experience, but that they cannot occur in isolation. How they interplay with one another is meaningful. However, the central characteristic of VR technology is the degree of immersion that such a system could potentially deliver (Peukert et al., 2019). According to Baus and Bouchard (2014), the level of immersion is caused by the number and the level of interactions and the extent and realism of actions implemented in the virtual environment. Tcha-Tokey et al. (2018) described immersion in more detail, as the objective rank of sensory visual fidelity in the context of a virtual reality system that is built by complex technologies that replace real-world sensory data with synthetic stimuli.

In the study presented in this paper, the researchers focus on VR applications in shopping environments. How this technology is already used in the context of online shopping and which potential it has in this context is explained in the next chapter.

\section{Virtual Reality in Online Shopping}

Companies' interest in Virtual Reality is increasing, because VR technology has entered mass markets. For example, VR is already used in shopping applications (Peukert and Meissner, 2019). The latest technologies (e.g., Internet of Things, robots), new business models (e.g., subscription models), and the predictive analytic possibilities using big data, indicate that the shopping process is on the threshold of a quantum leap into an unknown field (Grewal et al., 2017). Virtual Reality technology could contribute to an especially big change with regard to online shopping. Enriching consumers' sensorial engagement could lead to a more positive shopping attitude and more real perception of products (Lau et al., 2013).

Seidl (2018) stated that purchasing decisions are influenced visually. In fact, a study by Domina et al. (2012) showed that being in a virtual retail business environment engages consumers much more than being in a conventional online shopping setting. Therefore, it is not surprising that in the meantime companies have already exploited the potential of VR shopping. Companies like YouVisit provide experimental marketing to consumers and businesses. This company offers an easy-to-use VR platform in order to remove fearful barriers of entry into commerce, i.e. you do not have to make any programming effort because these wideranging applications already provide all you need. For example, they are capable of providing avatars, which can carry on selling or which can make offers (Adams, 2016). 
Caraciolo (2016) points out that product experiences such as a car model with specific equipment to walk through, or exploring of holiday destinations in advance, are typical applications of Virtual Reality.

Architectural environments and apartment visits are self-explanatory in VR, and special VR experiences in showrooms or amusement parks are already in use.

For instance, SATURN, Europe's largest retailer for consumer electronics, has already launched the Virtual SATURN shopping environment. One of the first in the trade sector, SATURN introduced VR technology in their stationary retail. The customers could choose between three different virtual apartments, with products from Bosch, Siemens, and AEG, and even choose their preferred surroundings - from a country house to penthouse apartment with roof terrace. Clients who have tried out the Saturn Virtual Reality Showroom were increasingly willing to recommend the experience (Seidl, 2018).

In addition, worldwide VR shopping applications already exist, such as the Chinese e-commerce company Alibaba, the US department store Macy's, or the Swedish company IKEA. These multinational enterprises experimenting with VR shopping applications presumably see the technology as an opportunity to create a competitive advantage (Inman and Nikolova, 2017).

In this respect, the profitable online shop of Merrell, a shoe and textile brand, created a virtual hike, motiontracked with multi-sensory elements, where users could walk over shaky bridges, climb walls, and fully experience the outdoors through their VR app (Carter, 2018). Another example is the clothing outdoor company North Face, which has developed an in-store application where customers are provided with the VR experience of hiking, rock climbing, and base-jumping. In addition, they were supported in their decision-making process while buying gear in the store. As a result, VR technologies could create additional value (Barnes, 2017).

Also several researchers found the potential for companies to create persuasive brand messages and valueadding, novel experiences for their customers in a VR environment (e.g. (Bulearca and Bulearca, 2012; Denegri-Knott and Molesworth, 2010; Spaulding, 2010).

In the study by Gua and Barnes (2009), results showed that enjoyment plays a significant role in motivating individuals to pursue new items in virtual settings. The strongest effect on shopping intention occurred when consumers perceived pleasure. Lee and Chung (2008) also found out that the same construct was an important criterion for customer satisfaction when visiting a virtual reality shopping mall.

Other researchers substantiate that a novel, exciting, and engaging shopping experience could positively affect consumers' buying behavior (Pantano and Naccarato, 2010). However, more than technology, content is the key to the success of VR. According to the business unit leader of the Technology Research Group Goldman Sachs Research, Bellini (2016), the VR branded content market could be worth $\$ 80$ billion by 2025.

VR could also provide a way to connect consumers with products and services prior to buying, and also give them a way to immerse themselves in their brand. For that reason, the Forbes Agency Council (2018) came to the conclusion that integration of Virtual Reality will spread further across all industries. With this boost of virtual technology development, the consumer's shopping experience could be enriched, allowing a unique form of time and space that is substantially different from 2D web-based shopping (Lau et al., 2013).

Peukert et al. (2019) investigating across two different shopping environments, found that participants valued the utilitarian and particularly the hedonic dimensions of VR shopping, which indicates that investments in building VR shopping environments could be profitable for retailers and customers.

To sum up, online shopping in a Virtual Reality environment could provide many benefits. However, is it actually more profitable than shopping in a conventional online store?

\section{Empirical Study}

The empirical study presented in this paper contributes to answer the research question of whether this new and innovative way of online shopping, which uses Virtual Reality technology to offer the products, is more suited to selling objects compared to the conventional online shopping format, with its non-immersive and two-dimensional presentation of the products. 


\subsection{Method}

In the present study, three conditions were compared (see Tab. 1): In the first condition, the participants first saw sports shoes in a conventional online shop format, that is, in a non-immersive format containing some two-dimensional pictures of the shoes. After that, the participants were presented with a smartwatch in a Virtual Reality online shop, that is, they could take the watch in their hands by means of the controllers and view it from all sides.

In the second condition, the participants first saw the smartwatch in a conventional online shop format.

Thereafter the participants were confronted with the sports shoes in a virtual reality online shop. The second condition was necessary to ensure that there were no effects caused by the kind of products.

In the third condition, both objects, the smartwatch and the sports shoes, were presented in the Virtual Reality online shop. Half of participants first saw the smartwatch followed by the sports shoes (see Tab. 1, condition 3a). The other half of participants were first confronted with the sports shoes and afterwards with the smartwatch (see Tab. 1, condition 3b). This third condition was necessary to exclude the effects of seeing objects in a conventional way and in a VR context.

Table 1: Description of the three conditions (own resource)

\begin{tabular}{|l|l|l|l|}
\hline & $\begin{array}{l}\text { First object the } \\
\text { participants saw }\end{array}$ & $\begin{array}{l}\text { Second object the } \\
\text { participants saw }\end{array}$ & $N$ \\
\hline Condition 1 & sports shoes in 2D & smartwatch in VR & 18 \\
\hline Condition 2 & smartwatch in 2D & sports shoes in VR & 16 \\
\hline Condition 3a & smartwatch in VR & sports shoes in VR & 8 \\
\hline Condition 3b & sports shoes in VR & smartwatch in VR & 8 \\
\hline
\end{tabular}

A fourth condition presenting both objects in a conventional way, that would allow a $2 \times 2$ between-design was not investigated, because we were only interested in effects caused by products presented in a VR-based online shop.

\subsubsection{Participants}

Fifty participants (20 female, 30 male) took part in the study. Most of them were students from a university of applied sciences in Germany from different fields of study $(\mathrm{N}=42)$, that is, they had a university-entrance diploma. One further participant had a master's degree, four participants had a doctoral degree, and three participants chose not to mention their education level. The average age was 23.15 years $(\mathrm{SD}=7.38)$. They volunteered to participate. The participants were randomly assigned to one of the three conditions.

We conducted one-factorial analyses of variance for all dichotomous and interval-scaled control variables as well as a chi-squared test for the control variable education status. There were no significant differences between the three conditions regarding all control variables. Therefore, the inclusion of a covariate in further calculations was not necessary.

\subsubsection{Materials and Setting}

As already mentioned, the participants were confronted with a smartwatch and with sports shoes. These two objects were chosen for the study because they seemed to be gender neutral, that is, both objects could be bought by women and by men. Figure 1 shows pictures of the two products presented. 


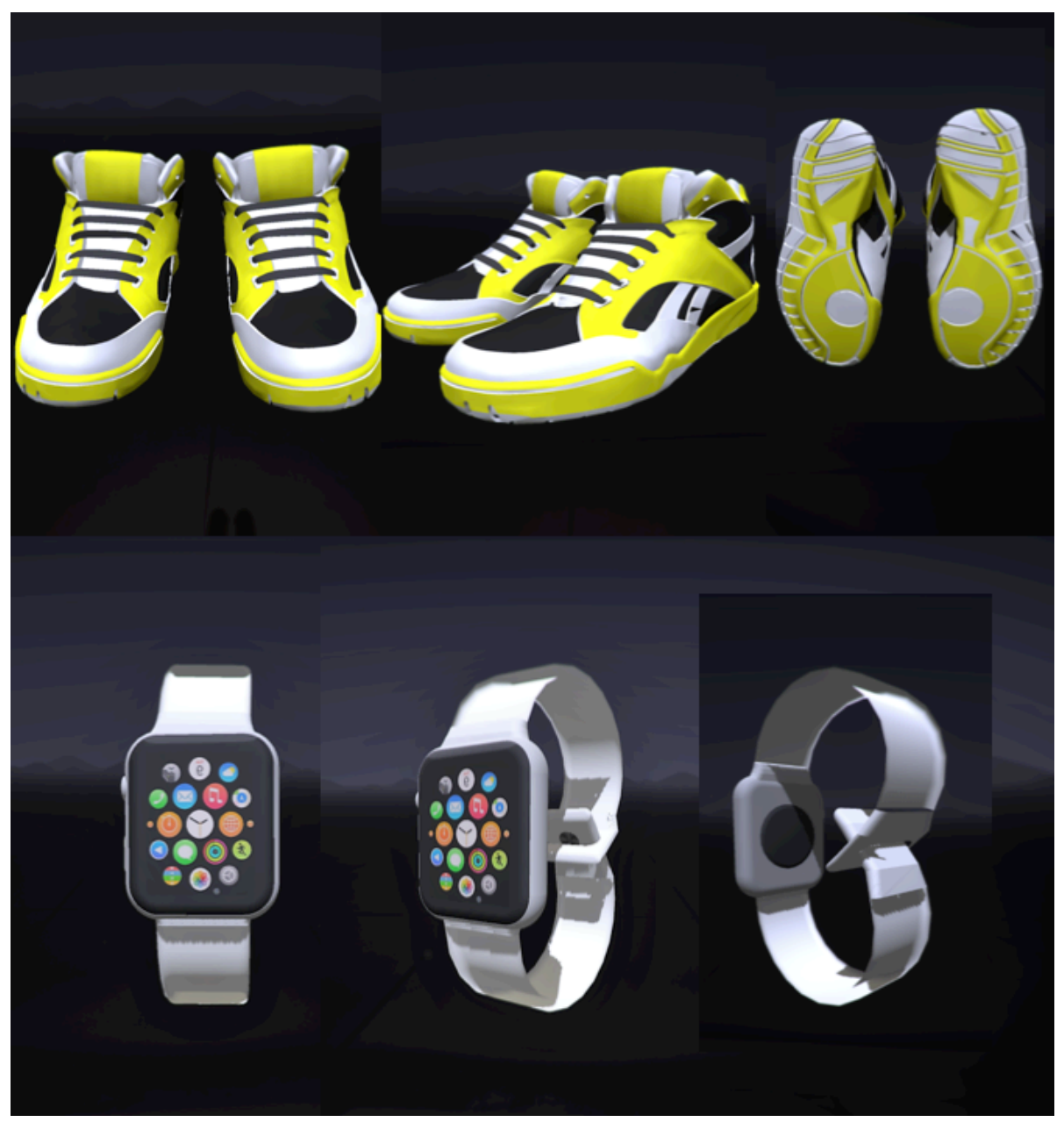

Figure 1: Pictures of the sports shoes (above) presented and of the smartwatch (below) presented.

Several questionnaires, filled out individually, were used in the study: First, participants filled out a questionnaire to assess control measure items, such as demographical data, experience with new technologies, especially with Virtual Reality technologies, online shopping behavior and preferences. The questionnaire included on one side questions with an open format and on the other side multiple-choice questions that were designed either as five-point rating scales ranging from complete agreement to no agreement or as dichotomous items with two options for choice. The questionnaire, containing 11 questions, is presented in appendix A.

Second, a questionnaire was generated to assess the intention to buy the presented products, the liking of the presented products, the evaluation of the objects in accordance with their perceived reality level, as well as their evaluation of online shopping in a virtual reality. The items were assessed again by five-point rating scales ranging from 1 point for no agreement to 5 points for complete agreement. The questionnaire contained 13 questions. It is attached in appendix B.

Third, a knowledge test was developed to assess the knowledge acquired from the objects while being presented with them (see appendix C). The items were assessed by six multiple-choice questions, each providing four different possible answers as well as the answer "I do not know anymore". There was only one correct answer in each of the items.

The participants were invited to a Virtual Reality lab. To fill out the questionnaires they sat at a table. To see the objects in the Virtual Reality shop, they wore Oculus VR classes and used the Oculus controllers. While in the Virtual Reality shop they were allowed to move freely in the room. In order to see the product in a conventional online shop, the participants sat in front of a computer and saw the products on the monitor. Here, they saw different pictures of the presented product, each presenting a different perspective of the 
product (see Fig. 1). This was important to make sure we were providing the same information in the VR shop and the conventional online shop.

\subsubsection{Procedure}

First, each participant was asked to fill out the questionnaire to measuring control measure items. After that, in the conditions one and two, first the conventional online shop was presented, before the participants were confronted with the object in the virtual reality-based shop. In the third condition, the participants entered the VR-based shop only. In the third condition, half of the participants first saw the smartwatch, while the other half of the participants viewed the sports shoes first.

Afterwards, the participants completed the questionnaire for assessing the intention to buy the presented products, the liking and evaluation of the presented products, as well as for evaluating online shopping in Virtual Reality. They also completed the knowledge test to assess the knowledge acquired from the objects while being presented with them. Finally, the participants were thanked and got some sweets. The duration for participation in the study was about 15 minutes for each participant.

\subsection{Hypotheses}

Due to the feeling of presence in the virtual reality and the possibility of perceiving the shopping items in a more natural format, combined with the possibility of interacting with the objects, similar to a real life shopping experience, it was assumed that the participants in the VR situation would acquire more knowledge about the shopping items, would develop a stronger liking and a better evaluation regarding the shopping objects, and would therefore report a higher interest in buying the objects, compared to participants in a conventional shopping situation. We derived the following hypotheses:

- Hypothesis 1: In the VR situation the participants will acquire more knowledge about the shopping items compared to the participants in the conventional online shopping situation.

- Hypothesis 2: In the VR situation the participants will develop a more positive attitude, in the sense of liking the shopping items, compared to the participants in the conventional shopping situation.

- Hypothesis 3: In the VR situation the participants will evaluate the shopping items as more real compared to the conventional online shopping situation.

- Hypothesis 4: In the VR situation the participants will more often show interest in buying the presented shopping items, compared to the participants in the conventional online shopping situation.

- Hypothesis 5: The participants will evaluate VR shopping positively.

\subsection{Dependent Measures}

The dependent variables constitute the amount of acquired knowledge about the shopping objects, the attitude in the sense of liking the shopping objects, the evaluation of the objects with regard to their perceived level of reality, the intention to buy the shopping objects, and the evaluation of VR shopping. All these dependent measures were assessed by questionnaires (see section 5.1.2). The distribution of all these dependent measures was tested for each condition, because normal distribution is a main requirement for calculating (M)ANOVAs. The Shapiro-Wilk-Tests showed that almost all dependent measures were not normally distributed for each condition $(\mathrm{p}<.05)$. Only with regard to five items (items $4,8,9,10$ of the second questionnaire and item "amount of knowledge w.r.t. shoes") the distribution of one of the three conditions was normally distributed ( $\mathrm{p}>.05$ ). However, (M)ANOVAs are robust methods that could be used also when the measures did not have a normal distribution (e.g. Blanca et al., 2017).

\section{Results}

Please note that in the following analyses the data of the smartwatch and the sport shoes were analyzed separately. 


\subsection{Results to Test Hypothesis 1 Focusing on the Acquired Knowledge}

There were three knowledge test items measuring the knowledge of the shoes and there were three knowledge test items that assessed the knowledge of the watch. If a participant gave a correct answer, one point was given. If the participant answered wrongly, he or she received 0 points. That is, three points were the maximum for the shoes knowledge questions and also three points could be reached as maximum with the watch knowledge questions. The minimum in both knowledge parts was 0 points.

\subsubsection{Results with regard to the smartwatch}

To test hypothesis 1 we conducted a one-factorial ANOVA with the three conditions as the independent measure and the knowledge test sum score on the smartwatch items as the dependent measure. It resulted in a significant difference $(\mathrm{F}(2,47)=3.28 ; \mathrm{p}<.05 ; \mathrm{M} 1=1.33, \mathrm{SD} 1=.69 ; \mathrm{M} 2=.69, \mathrm{SD} 2=.88 ; \mathrm{M} 3=1.25, \mathrm{SD} 3=.77)$. This is confirmed by the LSD post-hoc-tests comparing conditions 1 and $2(\mathrm{p}<.05)$ as well as comparing conditions 3 vs. $2(p<.05)$. In the second condition, the watch was presented in a conventional way, while in the other two conditions the watch was presented with VR technology. This means that when presenting the watch in VR, the participants acquired more knowledge on it compared to presenting it in a two-dimensional way.

To sum up, the hypothesis 1 could be confirmed with regard to the smartwatch.

\subsubsection{Results with regard to the sport shoes}

However, a one-factorial ANOVA, with the three conditions as the independent measure and the knowledge test sum score on the shoes items as the dependent measure, showed that there was no significant difference between the three conditions $(\mathrm{F}<1)$.

To sum up, the hypothesis 1 could not be confirmed with regard to the sports shoes.

\subsection{Results to Test Hypothesis 2 Focusing on the Attitude in Terms of Liking the Shopping Objects}

6.2.1. Results with regard to the smartwatch

To examine hypothesis 2, postulating a stronger liking of the objects in VR situations compared to the objects in conventional online shopping situations, we conducted a one-factorial ANOVA with the three conditions as the independent measure and the item "I think the smartwatch I saw is beautiful" as the dependent measure. There was no significant difference between the three conditions $(F(2,47)=1.52 ; p=.23$; $\mathrm{M} 1=3.78, \mathrm{SD} 1=.81 ; \mathrm{M} 2=3.19, \mathrm{SD} 2=1.47 ; \mathrm{M} 3=3.81, \mathrm{SD} 3=1.11$ ).

Therefore, the hypothesis 2 could not be confirmed for the smartwatch.

\subsubsection{Results with regard to the sports shoes}

We also conducted a one-factorial ANOVA with the three conditions as the independent measure, and the item "I think the sports shoes I saw are beautiful" as the dependent measure. There was a significant difference between the three conditions $(\mathrm{F}(2,47)=4.08 ; \mathrm{p}<.05 ; \mathrm{M} 1=2.11, \mathrm{SD} 1=1.08 ; \mathrm{M} 2=3.31$, SD2 $=1.35$; $\mathrm{M} 3=2.81, \mathrm{SD} 3=1.28)$. The LSD post-hoc tests showed a significant difference between conditions 1 and $2(\mathrm{p}$ $<.01)$. Only in condition 1 were the shoes presented in a two-dimensional matter. Therefore, the results showed that when presenting the shoes in VR the participants considered the shoes more beautiful than when presented in the conventional matter, but this was only the case if the participants were confronted with both the conventional way of presenting objects as well as with the Virtual Reality one. If both objects were presented with VR (see condition 3), there was no significant difference between the two-dimensional presentation and the VR presentation.

To sum up, the hypothesis 2 could be partly confirmed for the sports shoes. 


\subsection{Results to Test Hypothesis 3 Focusing on the Evaluation of the Shopping Objects as Real}

\subsubsection{Results with regard to the smartwatch}

In order to test hypothesis 3, we used a MANOVA with the three conditions as the independent measure and the items "The presentation of the smartwatch I saw was detailed", "Due to the way the smartwatch was displayed, I was able to imagine it well in reality", and "The smartwatch I saw seemed real to me" as the dependent measures.

The multivariate tests were significant (Pillai-Spur: $\mathrm{F}(6,92)=6.08, \mathrm{p}<.001$ ). Regarding the item "The presentation of the smartwatch I saw was detailed" the conditions differed significantly $(\mathrm{F}(2,47)=9.17$; $\mathrm{p}<.001 ; \mathrm{M} 1=4.11, \mathrm{SD} 1=.83 ; \mathrm{M} 2=2.59, \mathrm{SD} 2=1.05 ; \mathrm{M} 3=3.75, \mathrm{SD} 3=1.29)$. The LSD post-hoc-tests showed a significant difference between the conditions 1 and $2(\mathrm{p}<.001)$ and between the conditions 2 and $3(\mathrm{p}<.01)$. Only in condition 2 was the watch presented in a conventional way. This means that the participants received the presentation of the smart watch in the VR as more detailed compared to the presentation in a conventional way, independently of the presentation of all objects in VR (condition 3), or of a mixed presentation in VR and in a two-dimensional way (condition 1).

Regarding the item "Due to the way the smartwatch was displayed, I was able to imagine it well in reality" the conditions differed significantly $(\mathrm{F}(2,47)=23.77 ; \mathrm{p}<.001 ; \mathrm{M} 1=4.78, \mathrm{SD} 1=.43 ; \mathrm{M} 2=2.75$, SD2=1.13; $\mathrm{M} 3=4.06, \mathrm{SD} 3=.93)$. The LSD post-hoc-tests showed significant differences between the conditions 1 and 2 $(\mathrm{p}<.001)$, between conditions 2 and $3(\mathrm{p}<.001)$, and between conditions 1 and $3(\mathrm{p}<.05)$. This means that the participants seeing the presentation of the smartwatch in the VR could imagine the smartwatch better in reality compared to participants seeing the watch in a conventional way, independently of the presentation of all objects in VR or a mixed presentation in VR and in a two-dimensional way. However, in addition, the effect was yet stronger if the two objects were presented in a mixed kind of presentation.

Regarding the item "The smartwatch I saw seemed real to me" the conditions differed significantly $(\mathrm{F}(2,47)=19.03 ; \mathrm{p}<.001 ; \mathrm{M} 1=4.29, \mathrm{SD} 1=.83 ; \mathrm{M} 2=2.19, \mathrm{SD} 2=.83 ; \mathrm{M} 3=3.38, \mathrm{SD} 3=1.20)$. The LSD post-hoctests showed significant differences between the conditions 1 and $2(\mathrm{p}<.001)$, between conditions 2 and $3(\mathrm{p}$ $<.001)$, and between conditions 1 and $3(\mathrm{p}<.05)$. This means that for the participants receiving the presentation of the smartwatch in the VR, the smartwatch appeared more real compared to participants seeing the watch in a conventional way, independently of the presentation of all objects in VR or of a mixed presentation in VR and in a two-dimensional way. However, in addition, the effect was yet stronger if the two objects were presented in a mixed kind of presentation.

To sum up, hypothesis 3 could be confirmed for the smartwatch.

\subsubsection{Results with regard to the sports shoes}

In addition, a MANOVA was conducted with the three conditions as the independent measure and the items "The presentation of the sports shoes I saw was detailed", "Due to the way the sports shoes were presented, I could imagine them well in reality" and "The sports shoes I saw seemed real to me" as the dependent measures.

The multivariate tests were significant (Pillai-Spur: $\mathrm{F}(6,92)=5.31, \mathrm{p}<.001$ ). Regarding the item "The presentation of the sport shoes I saw was detailed" the conditions differed significantly $(\mathrm{F}(2,47)=13.37$; $\mathrm{p}<.001 ; \mathrm{M} 1=2.61, \mathrm{SD} 1=1.04 ; \mathrm{M} 2=4.25, \mathrm{SD} 2=.58 ; \mathrm{M} 3=4.0, \mathrm{SD} 3=1.26)$. The LSD post-hoc-tests showed significant difference between the conditions 1 and $2(p<.001)$ and between conditions 1 and $3(p<.001)$. This means that the participants perceived the presentation of the shoes in the VR as more detailed compared to participants seeing the sports shoes in a conventional way, independently of the presentation of all objects in VR or of a mixed presentation in VR and in a two-dimensional way.

Regarding the item "Due to the way the sports shoes were presented, I could imagine them well in reality" the conditions differed significantly $(\mathrm{F}(2,47)=16.56 ; \mathrm{p}<.001 ; \mathrm{M} 1=3.06, \mathrm{SD} 1=1.16 ; \mathrm{M} 2=4.75, \mathrm{SD} 2=.45$; $\mathrm{M} 3=4.25, \mathrm{SD} 3=.86$ ). The LSD post-hoc-tests showed significant differences between the conditions 1 and 2 $(\mathrm{p}<.001)$ and between the conditions 1 and $3(\mathrm{p}<.001)$. This means that the participants receiving the presentation of the shoes in the VR could imagine the shoes better in reality compared to participants 
receiving the presentation in a conventional way, independently of the presentation of all objects in VR or of a mixed presentation in VR and in a two-dimensional way.

Regarding the item "The sports shoes I saw seemed real to me", the conditions differed significantly $(\mathrm{F}(2,47)=13.82 ; \mathrm{p}<.001 ; \mathrm{M} 1=2.22, \mathrm{SD} 1=.94 ; \mathrm{M} 2=4.13, \mathrm{SD} 2=.1 .02 ; \mathrm{M} 3=3.5, \mathrm{SD} 3=.1 .26)$. The LSD posthoc-tests showed significant differences between the conditions 1 and $2(p<.001)$ and between the conditions 1 and $3(\mathrm{p}<.001)$. This means that the participants perceiving the presentation of the shoes in the VR could imagine the shoes better in reality compared to participants perceiving the presentation in a conventional way, independently of the presentation of all objects in VR or of a mixed presentation in VR and in a two-dimensional way.

To sum up, hypothesis 3 could be confirmed for sports shoes, too.

\subsection{Results to Test Hypothesis 4 Focusing on the Intention to Buy the Shopping Objects}

\subsubsection{Results with regard to the smartwatch}

In order to test hypothesis 4, we conducted a one-factorial ANOVA with the conditions as the independent measure and the intention to buy the smartwatch as the dependant measure. The results showed that the conditions differed significantly regarding their intention to buy the watch $(\mathrm{F}(2,47)=4.03 ; \mathrm{p}<.05 \mathrm{M} 1=3.56$, $\mathrm{SD} 1=1.10 ; \mathrm{M} 2=2.38, \mathrm{SD} 2=1.02 ; \mathrm{M} 3=3.06, \mathrm{SD} 3=1.48)$. The LSD post-hoc tests showed a significant difference between the conditions 1 and $2(\mathrm{p}<.01)$. This means that when presenting the watch in VR the participants mentioned more often the intention to buy the watch compared to the participants that saw it in a two-dimensional way, but this was only the case if the participants were confronted with both the conventional way of presenting objects as well as with the VR one. If both objects were presented with VR (see condition 3), there was no significant difference between the VR presentation and the two-dimensional presentation.

To sum up, the hypothesis 4 could be partly confirmed for the smartwatch.

\subsubsection{Results with regard to the sports shoes}

In addition, we conducted a one-factorial ANOVA with the conditions as the independent measure and the intention to buy the sports shoes as the dependant measure. The results showed that the conditions differed by trend regarding their intention to buy the shoes $(\mathrm{F}(2,47)=2.98 ; \mathrm{p}<.1 ; \mathrm{M} 1=2.00, \mathrm{SD} 1=.91 ; \mathrm{M} 2=2.88$, $\mathrm{SD} 2=1.31 ; \mathrm{M} 3=2.88, \mathrm{SD} 3=1.41)$. The LSD post-hoc tests showed significant differences between the conditions 1 and $2(\mathrm{p}<.05)$ and between the conditions 1 and $3(\mathrm{p}<.05)$. Only in condition 1 were the shoes presented in a two-dimensional manner. Therefore, the results showed that when presenting the shoes in VR the participants mentioned more often the intention to buy the shoes compared to the participants that saw them in a two-dimensional way.

To sum up, the hypothesis 4 could be confirmed for the shoes.

\subsection{Results to Test Hypothesis 5 Focusing on the Evaluation of the VR Shopping Experience} In order to test hypothesis 5 descriptive analyses were conducted (see Tab. 2): The descriptive statistics showed that the participants of all conditions could imagine that in future they would buy in an online shop that offers items in VR. In addition, they all stated that VR shopping is exciting and they all pointed out the importance of moving and touching the objects in a Virtual Reality shop.

Therefore, hypothesis 5 could be confirmed. 
Table 2: Descriptive statistics of the three items "I could imagine shopping in an online shop in the future, in which the objects for sale are represented in a virtual reality" (N11), "Shopping in a virtual reality is exciting for me" (N12) and "It is important to me that I can touch and move the object of purchase in a virtual environment" (N13) for the three conditions (own resource).

\begin{tabular}{|l|l|l|l|l|}
\hline \multirow{4}{*}{ N11_VR shopping in future } & conditions & $M$ & $S D$ & $N$ \\
\cline { 2 - 5 } & 1 & 4.722 & .7519 & 18 \\
\cline { 2 - 5 } & 2 & 4.250 & 1.0000 & 16 \\
\cline { 2 - 5 } & sum & 4.187 & .8342 & 16 \\
\hline \multirow{4}{*}{$\begin{array}{l}\text { N12_excitement of VR } \\
\text { shopping }\end{array}$} & 1 & 4.400 & .8806 & 50 \\
\cline { 2 - 5 } & 2 & 4.889 & .3234 & 18 \\
\cline { 2 - 5 } & 3 & 4.313 & 1.0145 & 16 \\
\cline { 2 - 5 } & Sum & 4.563 & .8921 & 16 \\
\hline \multirow{2}{*}{$\begin{array}{l}\text { N13_importance of moving } \\
\text { touching }\end{array}$} & 1 & 4.600 & .8081 & 50 \\
\cline { 2 - 5 } & 2 & 4.556 & .6157 & 18 \\
\cline { 2 - 5 } & 3 & 4.188 & .7500 & 16 \\
\cline { 2 - 5 } & sum & 4.250 & .7746 & 16 \\
\hline
\end{tabular}

An exploratory MANOVA was conducted, with the three conditions as the independent measure and the items "I could imagine shopping in an online shop in the future, in which the objects for sale are represented in a virtual reality", "Shopping in a virtual reality is exciting for me", and "It is important to me that I can touch and move the object of purchase in a virtual environment" as the dependent measures. The multivariate tests were not significant (Pillai-Spur: $\mathrm{F}(6,92)=1.31, \mathrm{p}=.26$ ). The conditions did not significantly differ with regard to the intention to buy in future objects in VR shops. The three conditions did not differ significantly regarding the excitement of shopping in VR. There was also no significant difference regarding the wish for touching and moving the VR objects.

\section{Discussion of the Study Results}

The study showed interesting results: Although the participants acquired more knowledge regarding the smartwatch in the VR situations compared to the participants in the conventional situations, there were no significant differences regarding the liking of the object between the conventional and the VR situation. In contrast, there were no significant differences between the conventional and the VR situations regarding the acquired knowledge of the sports shoes. However, the participants in the (mixed) VR situation liked the sports shoes more compared to participants in the conventional shopping situation.

These results may be a hint that being able to acquire more knowledge about shopping objects does not necessarily influence the liking of an object, and vice versa. However, this is maybe caused by the different kinds of objects. Further studies need to be conducted to be able to explain these findings.

Hypothesis 1, postulating that in a VR shopping situation more knowledge is acquired compared to the conventional online shopping, could therefore only be confirmed with the smartwatch, but not with the sports shoes. This could be explained by the kind of objects. Maybe in case of buying a smartwatch, it is much more important to acquire knowledge about the object than in the case with sports shoes, as shoes only need to fit and be appealing. We do not necessarily need detailed knowledge on shoes.

Hypothesis 2 postulated that in a VR shopping situation, the participants will like the items more compared to participants that saw the items in a conventional way. As already mentioned, this could only be confirmed for the shoes, but not for the watch. Perhaps it is more expressive to see sports shoes in VR as a smartwatch, because in reality a watch is flatter, that is, a more two-dimensional object, and shoes are more bulky - that is, there is a stronger three-dimensionality. 
With regard to hypothesis 3, expecting a more real perception of the shopping items in VR compared to in a conventional shop, the expectations could be confirmed with regard to both objects. The smartwatch and the sports shoes were perceived as more detailed in the VR situation, the participants could better imagine that the objects were real, and they stated that the objects appeared more real in the VR situation compared to the participants in the conventional shopping situation. This chimes in with the corresponding literature showing that objects in VR could be presented in a more real manner (e.g. (Sobieraj and Krämer, 2016)).

In addition, hypothesis 4 could also be confirmed with regard to both objects: The participants in a VR situation stated more often that they would buy the object compared to the participants in the conventional situation. This underpinned the assumption that it is valuable for organizations to present their products in VR. This is in line with the findings from other research (e.g. (Domina et al., 2012)).

Furthermore, it could be shown that shopping in VR was perceived as exciting. It was also shown that the participants plan to buy in future in VR shops. Displaying one of the main advantages of VR, it could be shown that participants want to touch and move objects when they buy them in a VR store. This is not possible in conventional online shops. This confirmed hypothesis 5 . These results are in line with the results of other studies (e.g. (Domina et al., 2012)).

\section{Limitations of the Study and Conclusions}

Some methodological aspects have to be mentioned: The study conducted was an experimental study with a focus on internal validity. This means we wanted to show that the variations in the independent measures have causal effects on the dependent measures, i.e., that differences in the acquired knowledge regarding the shopping items, the attitudes towards the shopping items, the perception of the shopping items, and the intention to buy the shopping items are caused by changes in the presentation type of the shopping items (two-dimensional vs. VR-based presentation). This is only possible in pure experimental studies. However, a focus on internal validity comes along with limitations regarding the external validity (e.g. (Hussy et al., 2013). Therefore, it has to be added that the results of this study could not easily be transferred to real contexts, because the study materials were - due to the focus on the internal validity - rather artificial. Therefore, further empirical studies are necessary with a stronger focus on external validity, to enable a stronger transfer of the results to real shopping situations. However, with a stronger focus on external validity, there would be more confounding variables included in the study, reducing the causal explanatory power.

Also, the following aspects limit the potential to generalize our findings to real online shopping situations: In our study there were no other shop features to see in the online shops, for example shelving with other products. Due to the fact that we used screenshots of the VR-objects in the conventional condition, the object presentations were not as appealing as would be the case in a real conventional online shop. We chose this method because - as already mentioned - we focussed in this first study on the internal validity, i.e. the objects in both conditions needed to be broadly identical to avoid confounding variables. In addition, the chosen objects for the Virtual Reality condition appeared a little bit artificial, because at this time we were not able to develop our own virtual reality objects and had to use existing ones. These factors need to be considered also with regard to the findings corresponding to hypothesis 3 , showing that in the VR condition, compared to the conventional condition, the shopping objects were evaluated as more real.

Therefore, as already mentioned above, in further studies it is important to realize more external validity, so as to be more able to generalize the empirical results into real shopping situations.

Furthermore, we only used two objects. These objects were from different fields. In a real shopping situation, a buyer would take a look at different objects of the same field, and will compare these objects, will evaluate them and finally select one of these objects to buy.

In addition, in the current study it was not asked whether the participants are interested in buying new sports shoes or a new smartwatch. We told them in the cover story that a family member will defray the costs for the provided objects for them, to induce their interest. Therefore, further studies are needed to recreate a more real shopping situation. 
By means of the study design, it is not possible to exclude that some findings are based on a "wow" effect, i.e. that parts of the effects in the VR situation can be traced back to a novelty effect of the VR experience. It is possible that after a longer time the novelty effect will disappear and therefore the advantages of the VR experience to retailers. Here, long-term studies will be necessary.

It also has to be mentioned that our chosen study design with the three conditions 2Dshoes-VRwatch, VRshoes-2Dwatch, and VRshoes-VRwatch was rather complex. However, we have chosen our complex design in order to enable all participants the experience of shopping in a virtual environment. When being confronted with both, a conventional and a Virtual Reality shopping experience, we assume that the participants experience the difference with regard to the presentation type directly and possibly more strongly. To see whether it makes a difference to being confronted with both presentation types or only with the Virtual Reality one, we also included the condition VRshoes-VRwatch. In fact, it would have been possible to compare only a $2 \mathrm{D}$ and a $3 \mathrm{D}$ condition, but we think, in this case, we would have lost important information.

It would have been important to measure the amount of immersion and presence the participants felt while taking part in the study in order to be able to measure whether the amount of immersion or the feeling of presence are the reasons for the effects found in the virtual reality condition compared to the conventional condition. In further studies, it would be important to measure also the amount of immersion and the experience of presence. This would be possible by conducting qualitative interviews with some of the participants in order to get more qualitative data regarding the feeling of presence, flow, and further important concepts. Further studies could also use eye-tracking techniques to get more insight into the processes or to assess the time spent observing the objects.

Furthermore, only 50 participants took part in this study, of which the majority were university students. However, university students are not representative of the online shopping population.

In addition, we only measured the intention to buy the object, but not the act buying. According to the classic work of Fishbein and Ajzen (1975), it is important to differentiate between the intention and the corresponding act, because there could be factors that hinder an individual to transform his or her intention into action.

However, despite these mentioned limitations, in sum, this study gives first hints that it could be valuable for a retailer to develop and provide online VR shops.

\section{Acknowledgments}

This research project was supported by Macromedia University of Applied Sciences, Stuttgart, Germany.

\section{References}

Adams R.L., 2016. Five ways virtual reality will change the world. Retrieved from https://www.forbes.com/sites/robertadams/2016/10/17/5-ways-virtual-reality-will-change-theworld/\#31e939ee2b01

Barnes S.J., 2017. Understanding virtual reality in marketing: Nature, implications and potential. SSRN. Retrieved from https://doi.org/10.2139/ssrn.2909100

Baus O. and Bouchard S., 2014. Moving from virtual reality exposure-based therapy to augmented reality exposure-based therapy: A Review. Frontiers in Human Neuroscience, 8, 1-15. Retrieved from https://doi.org/10.3389/fnhum.2014.00112

Bellini H., 2016. Billion dollar babies: Retrieved from https://www.goldmansachs.com/insights/podcasts/episodes/03-23-2016-heather-bellini.html

Blanca M.J., Alarcón R., Arnau J., Bono R., Bendayan R., 2017. Non-normal data: Is ANOVA still a valid option? Psicothema, 29(4), 552-557. 
Brandt M., 2017. Facebook steigert Oculus-Absatz. Retrieved from

https://de.statista.com/infografik/10983/weltweiter-absatz-von-ar-und-vr-headsets/

Bulearca M. and Bulearca S., 2012. Virtual goods: Insanity or just a smart business model? International Journal of Innovation in the Digital Economy, 3 (3), 1-9.

Caracciolo L., 2016. 3 Gründe, warum Virtual Reality sich endlich durchsetzen wird. Digital pioneers. Retrieved from: https://t3n.de/news/3-gruende-virtual-reality-705762/

Carter C., 2018. These brands are using VR to offer customers. An exceptional experience. Retrieved from https://www.forbes.com/sites/forbesagencycouncil/2018/01/10/these-brands-are-using-vr-to-offercustomers-an-exceptional-experience-heres-how/\#21c1672841da

Cearley D., Burke B., Searle S., Walker M., 2017. Top 10 strategic technology trends for 2018. Gartner Research, 10, 1-9.

Chaffey D., Hemphill T., Edmundson-Bird D., 2019. Digital Business and E-Commerce Management. London: Pearson Education Limited.

Cheng L.K., Chieng M.H., Chieng W.H., 2014. Measuring virtual experience in a three-dimensional virtual reality interactive simulator environment: A structural equation modeling approach. Virtual Reality, $18,173-188$.

Csikszentmihalyi M., 1990. Flow: The psychology of optimal experience. New York: Harper and Row.

Denegri-Knott J. and Molesworth M., 2010. Concepts and practices of digital virtual consumption. Consumption Markets and Culture, 13 (2), 109-132.

Domina T., Lee S.-E., MacGillivray M., 2012. Understanding factors affecting consumer intention to shop in a virtual world. Journal of Retailing and Consumer Services, 19, 613-620.

Eurostat, 2018. E-Commerce statistics for individuals. Retrieved from https://ec.europa.eu/eurostat/statisticsexplained/pdfscache/46776.pdf

Fishbein M. and Ajzen I., 1975. Belief, attitude, intention, and behavior: An introduction to theory and research. Reading, MA: Addison-Wesley.

Forbes Agency Council, 2018. These brands are using VR to offer customers an exceptional experience. Here's how. Retrieved from https://www.forbes.com/sites/forbesagencycouncil/2018/01/10/thesebrands-are-using-vr-to-offer-customers-an-exceptional-experience-heres-how/\#21c1672841da

Gorisse G., Christmann O., Amato E.A., Richir, S., 2017. First- and third-person perspectives in immersive virtual environments: Presence and performance analysis of embodied users. Frontiers in Robotics and $A I, 4,1-12$.

Grewal D., Roggeveen A.L., Nordfält J., 2017. The Future of Retailing. Journal of Retailing, 93(1), 1-6.

Grudzewski F., Awdziej M., Mazurek G., Piotrowska K., 2018. Virtual reality in marketing communication the impact on the message, technology and offer perception. Economics and Business Review, 4, $24-$ 35.

Gua Y. and Barnes S., 2009. Virtual item purchase behavior in virtual worlds: An exploratory study. Electronic Commerce Research, 9, 77-96.

Hussy W., Schreier M., Echterhoff G., 2013. Forschungsmethoden in Psychologie und Sozialwissenschaften für Bachelor. Berlin: Springer.

Inman J.J. and Nikolova H., 2017. Shopper-facing retail technology: a retailer adoption decision framework incorporating shopper attitudes and privacy concerns. Journal of Retailing, 93 (1), 7-28.

Lau H.F., Kan C.W., Lau, K.W., 2013. How consumers shop in virtual reality? How it works? Advances in Economics and Business, 1(1), 28-38.

Laudon K.C. and Traver C.G., 2016. E-commerce 2016. Business. Technology. Society. Edinburgh: Pearson Education.

Leadem R., 2017. 67 fascinating facts about ecommerce vs. brick and mortar. Retrieved from https://www.entrepreneur.com/article/306678

Lee K.C. and Chung N., 2008. Empirical analysis of consumer reaction to the virtual reality shopping mall. Computers in Human Behavior, 24, 88-104. 
Mütterlein J., 2018. The three pillars of virtual reality? Investigating the roles of immersion, presence, and interactivity. Retrieved from http://hdl.handle.net/10125/50061

Nah F.F.-H., Eschenbrenner B., Zeng Q., Telaprolu V.R., Sepehr S., 2014. Flow in gaming: Literature synthesis and framework development, International Journal of Information Systems and Management, 1, 83-124.

NASA, 2016. Virtual reality: Definitions and requirements. Retrieved from https://www.nas.nasa.gov/Software/VWT/vr.html

Pantano E. and Naccarato G., 2010. Entertainment in retailing: the influences of advanced technologies. Journal of Retailing and Consumer Services, 17, 200-204.

Peukert C., Pfeiffer J., Meißner M., Pfeiffer T., Weinhardt C., 2019. Shopping in Virtual Reality Stores: The Influence of Immersion on System Adoption. Journal of Management Information Systems, 36(3), $755-788$.

Pillai J.S., Schmidt C., Richir S., 2013. Achieving presence through evoked reality. Frontiers in Psychology. Retrieved from: https://doi.org/10.3389/fpsyg.2013.00086

Plummer D. C., et al., 2016. Top Strategic Predictions for 2017 and Beyond: Surviving the Storm Winds of Digital Disruption. Retrieved from

https://www.gartner.com/binaries/content/assets/events/keywords/cio/ciode5/top_strategic_predictio ns_fo_315910.pdf

Riehm U., Petermann T., Orwat C., Coenen C., Revermann C., Scherz C., Wingert, B., 2003. E-Commerce in Deutschland. Eine kritische Bestandsaufnahme zum elektronischen Handel. Berlin: edition sigma.

Seidl D., 2018. Handel im Wandel durch virtuelle und erweiterte Realitäten. In M. Knoppe \& M. Wilde (Eds.), Digitalisierung im Handel (p. 223-233). Berlin: Springer.

Siepermann M., 2018. Electronic Shopping. In Gabler Wirtschaftslexikon (Eds.). Retrieved from https://wirtschaftslexikon.gabler.de/definition/electronic-shopping-36564/version-260015

Sobierja S. and Krämer N., 2016. Immersive virtuelle Umgebungen: Transformed Social Interaction, Proteus-Effekt und Persuasion. In N. Krämer, S. Schwan, D. Unz, D., \& M. Suckfüll (Eds.). Medienpsychologie: Schlüsselbegriffe und Konzepte (2nd Edition) (p. 397-404). Stuttgart: Kohlhammer.

Spaulding T.J., 2010. How can virtual communities create value for business? Electronic Commerce Research and Applications, 9, 38-49.

Steuer J., 1992. Defining virtual reality: Dimensions determining telepresence. Journal of Communication, 42(4), 73-93. Retrieved from https://doi.org/10.1111/j.1460-2466.1992.tb00812.x

Tcha-Tokey K., Christmann O., Loup-Escande E., Loup G., Richir, S., 2018. Towards a model of user experience in immersive virtual environments. Advances in Human-Computer Interaction, 2018. Retrieved from https://doi.org/10.1155/2018/7827286

Van Kerrebroeck H., Brengman M., Willems K., 2017. When brands come to life: experimental research on the vividness effect of Virtual Reality in transformational marketing communications. Virtual Reality, 21(4), 177-191.

Velev D. and Zlateva P., 2019. Analysis of v-Commerce as the New Online Sales Channel. International Journal of E-Education, e-Business, e-Management and e-Learning, 9(2), 131-137.

Virtual Reality Society, 2017. What is Virtual Reality? Retrieved from https://doi.org/10.3182/20100901-3$\underline{\text { IT-2016.00229 }}$ 